\title{
Evaluation of combustion, performance, and emissions of optimum palm-coconut blend in turbocharged and non-turbocharged conditions of a diesel engine
}

\author{
M.I. Arbab*, M. Varman, H.H. Masjuki, M.A. Kalam*, S. Imtenan, H. Sajjad, I.M. Rizwanul Fattah*
}

Center for Energy Sciences, Department of Mechanical Engineering, Faculty of Engineering, University of Malaya, 50603 Kuala Lumpur, Malaysia

A R T I C L E I N F O

Article history:

Received 19 June 2014

Accepted 8 November 2014

Available online 25 November 2014

\section{Keywords:}

Biodiesel

Fuel properties

Optimum blend

Engine performance

Engine emissions

\begin{abstract}
A B S T R A C T
Fossil fuel depletion, global warming with rapid changes in climate, and increases in oil prices have motivated scientists to search for alternative fuel. Biodiesel can be an effective solution despite some limitations, such as poor fuel properties and engine performance. From this perspective, experiments were carried out to improve fuel properties and engine performance by using a binary blend of palm and coconut biodiesel at an optimized ratio. MATLAB optimization tool was used to determine this blend ratio. A new biodiesel was developed and represented by PC (optimum blend of palm and coconut biodiesel). Engine performance and emission were tested under a full load at variable speed condition by using a $20 \%$ blend of each biodiesel with petroleum diesel, and the results were compared with petroleum diesel under both turbocharged and non-turbocharged conditions. PC20 (blend of $20 \%$ PC biodiesel and $80 \%$ petroleum diesel) showed the highest engine power with lower brake-specific fuel consumption than the other tested fuels in the presence of a turbocharger. The emissions of PC20 were lower than those of all other tested fuels. The experimental analysis reveals that PC showed superior performance and emission over palm biodiesel blend.
\end{abstract}

(c) 2014 Elsevier Ltd. All rights reserved.

\section{Introduction}

The global energy crisis, which is attributed to the depletion of fossil fuels and increasing environmental concerns, has motivated scientists to seek eco-friendly alternative sources of energy. To address this problem, researchers have been conducting studies for the last few decades [1-7]. One solution is the use of biodiesel, which is nontoxic and biodegradable [8,9]. The use of biodiesel minimizes greenhouse gas emission because of closed carbon cycle $[10,11]$. Biodiesel can sometimes extend engine component life $[12,13]$ and can be used in existing diesel engines without any modification [14]. However, minor modifications in engine fuel line components are sometimes recommended because biodiesel possesses some fuel properties that affect these components [15].

Many researchers conducted theoretical and experimental studies to improve (optimize), predict, and characterize biodiesel properties. Benjumea et al. [16] established prediction equations for kinematic viscosity, density, heating value, three different points of distillation curve, and calculated cetane index as a

\footnotetext{
* Corresponding authors. Tel.: +60 3 79674448; fax: +60 379675317 (M.I. Arbab).

E-mail addresses: arbab128@yahoo.com (M.I. Arbab), kalam@um.edu.my (M.A. Kalam), rizwanul.buet@gmail.com (I.M. Rizwanul Fattah).

function of the volume fraction of biodiesel in the blend. Later, they validated the equations experimentally, which shows that except for viscosity, other properties of binary mixture take the form of an arithmetic volume average. Alptekin and Canakci [17] experimentally studied the improvement of different fuel properties, namely, kinematic viscosity, density, pour point, flash point, and distillation characteristics in five different biodiesels (sunflower, canola, soybean, cottonseed, and corn oil) by blending with petroleum diesel at different ratios. Hussan et al. [18] tailored the viscosity of biodiesel by ethanol and a mathematically derived optimum formulation. They added this optimum palm biodieselethanol blend at varying proportions $(0-30 \%)$ with No. 2 diesel and studied various key fuel properties such as kinematic viscosity, derived cetane number ( $\mathrm{CN})$, flash point, cloud point, pour point, heating value, oxidation stability, specific gravity, and other properties. Some researchers also tried to improve fuel properties by using different additives. Rizwanul Fattah et al. $[19,20]$ and Palash et al. [21] used different antioxidant additives to improve oxidation stability and tested their effect on engine performance and emission. Imtenan et al. [22] reduced the density and increased the oxygen content of the blends by using oxygenated additives, and they tested their engine performance and emission characteristics. 
Previous studies on biodiesel indicate that its use in unmodified engines reduces brake power and increases fuel consumption. Xue et al. [23] studied more than 150 research endeavors and found that more than $50 \%$ confirmed higher thermal performance (efficiency), and approximately $45 \%$ indicated higher $\mathrm{NO}_{\mathrm{x}}$ emission, whereas more than $50 \%$ showed low $\mathrm{PM}, \mathrm{CO}$, and $\mathrm{HC}$ emission with the use of biodiesel blends. The low calorific value of biodiese results in higher brake thermal efficiency. Carraretto et al. [24 tested a six-cylinder diesel engine with diesel and biodiesel blend at different ratios and found a decrease in performance and CO emission but an increase in $\mathrm{NO}_{\mathrm{x}}$ emission. To aggregate the advantages of the high-ignition quality of palm and the high-oxygen content of coconut, the combined blend of this two biodiesels at a specific ratio was experimentally studied by Habibullah et al. [25]. They concluded that depending on performance and emission parameters, the combined blend shows superior performance and emission over individual biodiesel blends.

Although the use of additive-added blends improves some performance or emission aspects, these blends affect other parameters adversely. In addition, they are associated with high production costs. This study mainly aims to improve engine performance and emission by using biodiesel from a particular feedstock by blending with biodiesel from another feedstock, which has better properties in some aspects compared with the previous ones and thereby forming a binary mixture with improved properties. Although some research previously studied binary biodiesel mixture, they used common mixture ratios $[26,27]$. However, in this study an optimized ratio of binary biodiesel mixture, which improves overall fuel properties has been used. The ratio was obtained using MATLAB optimization tool, a method which has not been adopted by earlier studies. Palm and coconut biodiese were chosen because of their superior characteristics, such as a high $\mathrm{CN}$, high oxygen content, good ignition and combustion characteristics, and low pollutant emission [28,29]. In addition, Malay sia is one of the largest palm producers in the world, and its government has decided to use $40 \%$ (approximately 6 million tons) of the total palm produced annually as biodiesel. Later, experimental study was conducted to determine the effect of $20 \%$ blend of optimum binary biodiesel mixture with diesel on engine combustion, performance, and emissions.

\section{Optimum blending ratio calculation}

Experiments were conducted by using blends of palm and coconut-based biodiesel. Many researchers found that the most important fuel properties, such as density, kinematic viscosity, oxidation stability, flash point, calorific value, and $\mathrm{CN}$, vary linearly in the case of multiple biodiesel blends $[16,17,30,31]$. Thus, the linea relationship among fuel properties was considered to determine the optimum blending ratio, for which MATLAB optimization too was used. The optimization tool is a built-in tool of MATLAB 2012. It is a software that includes functions for linear programming, quadratic programming, binary integer programming, nonlinear optimization, nonlinear least squares, systems of nonlinear equations, and multi-objective optimization. MATLAB can be used to find optimal solutions, perform tradeoff analyses, balance multiple design alternatives, and incorporate optimization methods into algorithms and models.

To identify the optimum blending ratio, a number of boundary conditions were considered. The upper and lower limits for a specific fuel property were considered according to the highest and lowest values of the property of the individual fuels in the blend and according to the limit of the American Society for Testing and Materials (ASTM) standard. Meanwhile, for properties for which lower values are desired (e.g., viscosity and density), the median value of that specific fuel property was considered the highest limit. In the case of PC, palm had the lowest induction time, whereas coconut had the highest induction time. According to the ASTM standard, induction time should be at least $3 \mathrm{~h}$. Thus, the boundary condition was set to be higher than $3 \mathrm{~h}$. For example, if $A$ and $B$ are the values of a specific fuel property of three different fuels, then $X$ and $Y$ are the final blend ratios, respectively. Given that the maximum boundary limit for a specific fuel property value is $Q$ the equation used in MATLAB would be $(A X+B Y<Q)$. The optimized binary mixture ratio that satisfies all boundary conditions derived by the MATLAB optimization tool was $87.6 \%$ palm biodiesel and $12.4 \%$ coconut biodiesel.

\section{Experimental procedure}

\subsection{Improvement of fuel properties}

Engine performance and emission are directly affected by the physiochemical properties of fuel. These properties include density, viscosity, flash point, oxidation stability, $\mathrm{CN}$, iodine value and acid value. These properties indicate fuel quality. Among these properties, density, kinematic viscosity, oxidation stability, flash point, calorific value, and $\mathrm{CN}$ served as the focus of the researchers to determine fuel quality [32-34]. Different standards, such as ASTM, BS, and ISO, are used to define the properties of the fuel. These standards have defined the range of each fuel property. ASTM is the most widely followed standard among the others. To meet engine performance and emission requirements, the value of fuel properties must be within range.

In this experiment, new biodiesels with improved fuel properties were developed by blending palm (PB) and coconut (CB) biodiesel, considering two of them at a time. The apparatus used to identify the fuel properties is presented in Table 1, whereas the individual fuel properties of PB and CB are presented in Table 2 . Afterward, the MATLAB code was developed. The boundary conditions that were considered for the MATLAB optimization, as well as the optimum blend ratios, are listed in Table 3. The theoretical fuel property values for the blends were determined by using the optimum blend ratio and the linear equations. Lastly, the blends were prepared according to the optimum blend ratio. Afterward, the fuel properties of the optimum blend was tested in the laboratory (Table 4).

\subsection{Engine test}

The experiment was conducted by using an inline four-cylinder indirect injection, water-cooled, turbocharged diesel engine without any emission treatment system. The engine specifications are listed in Table 5. The BOSCH BEA-350 (specifications are listed in Table 6) exhaust gas analyzer was used for engine emission analysis. The schematic experimental setup is shown in Fig. 1. To carry out the tests using biodiesel blends, the engine was run with diesel

Table 1

Apparatus used for testing fuel properties.

\begin{tabular}{ll}
\hline Properties & Apparatus \\
\hline Density & $\begin{array}{l}\text { Stabinger viscometer SVM } 3000 \\
\text { Manufacturer: Anton Paar }\end{array}$ \\
Kinematic viscosity & $\begin{array}{l}873 \text { Biodiesel Rancimat } \\
\text { Induction time }\end{array}$ \\
Manufacturer: Metrohm \\
Fensky-Martens flash point-automatic NPM 440 \\
Calorific value & $\begin{array}{l}\text { Manufacturer: Normalab, France } \\
\text { Semi auto bomb calorimeter model: 6100EF } \\
\text { Manufacturer: Parr, USA }\end{array}$ \\
\hline
\end{tabular}


Table 2

Experimentally investigated individual fuel properties

\begin{tabular}{|c|c|c|c|c|}
\hline Properties & Standard and limit & Coconut biodiesel & Palm biodiesel & Diesel \\
\hline Density $\left(\mathrm{g} / \mathrm{cm}^{3}\right)$ & - & 0.8584 & 0.8592 & 0.8331 \\
\hline Induction time $(\mathrm{h})$ & EN14112 (3 h min) & 5.12 & 3.24 & - \\
\hline Flash point $\left({ }^{\circ} \mathrm{C}\right)$ & ASTM-D93 $\left(130^{\circ} \mathrm{C} \mathrm{min}\right)$ & 136.5 & 188.5 & 77.5 \\
\hline Cetane number ${ }^{3}$ & ASTM-D613 (47 min) & 60 & 55 & 49 \\
\hline
\end{tabular}

a Supplier given value.

Table 3

Boundary conditions and optimum blending/mixing ratio derived using MATLAB.

\begin{tabular}{|c|c|c|c|c|c|c|c|c|}
\hline \multirow[t]{2}{*}{ Blend content } & \multicolumn{6}{|c|}{ Boundary conditions } & \multicolumn{2}{|c|}{$\begin{array}{l}\text { Optimum blend/mixing } \\
\text { ratio (\%) }\end{array}$} \\
\hline & $\begin{array}{l}\text { Maximum } \\
\text { density }\left(\mathrm{g} / \mathrm{cm}^{3}\right)\end{array}$ & $\begin{array}{l}\text { Maximum kinematic } \\
\text { viscosity at } 40^{\circ} \mathrm{C}(\mathrm{cSt})\end{array}$ & $\begin{array}{l}\text { Minimum } \\
\text { induction time (h) }\end{array}$ & $\begin{array}{l}\text { Minimum } \\
\text { flash point }\left({ }^{\circ} \mathrm{C}\right)\end{array}$ & $\begin{array}{l}\text { Minimum calorific } \\
\text { value }(\mathrm{kJ} / \mathrm{g})\end{array}$ & $\begin{array}{l}\text { Minimum } \\
\text { cetane number }\end{array}$ & PB & СВ \\
\hline
\end{tabular}

Table 4
Experimental fuel properties of the optimum mix.

\begin{tabular}{clllll}
\hline Fuel & $\begin{array}{l}\text { Density } \\
\left(\mathrm{g} / \mathrm{cm}^{3}\right)\end{array}$ & $\begin{array}{l}\text { Kinematic } \\
\text { viscosity at } 40{ }^{\circ} \mathrm{C} \\
(\mathrm{cSt})\end{array}$ & $\begin{array}{l}\text { Induction } \\
\text { time }(\mathrm{h})\end{array}$ & $\begin{array}{l}\text { Flash } \\
\text { point } \\
\left({ }^{\circ} \mathrm{C}\right)\end{array}$ & $\begin{array}{l}\text { Calorific } \\
\text { value }(\mathrm{kJ} / \\
\mathrm{g})\end{array}$ \\
\hline PC & 0.8597 & 4.6295 & 3.66 & 180.5 & 38.5555 \\
\hline
\end{tabular}

Table 5

Engine test bed equipment specification

\begin{tabular}{ll}
\hline Description & Specification \\
\hline $\begin{array}{l}\text { No. and arrangement of } \\
\text { cylinders }\end{array}$ & 4 in-line, longitudinal \\
Rated power & $65 \mathrm{~kW}$ at $4200 \mathrm{rpm}$ \\
Torque & $185 \mathrm{~N} \mathrm{~m}$, at $2000 \mathrm{rpm}$ \\
Combustion chamber & Swirl chamber \\
Total displacement & $2477 \mathrm{cc}$ \\
Cylinder bore $\times$ stroke & $91.1 \times 95 \mathrm{~mm}$ \\
Valve mechanism & SOHC \\
Compression ratio & $21: 1$ \\
Lubrication system & Pressure feed, full flow filtration \\
Fuel system & Distributor type injection pump \\
Air flow & Turbocharged \\
Fuel injection pressure & 157 bar \\
Dynamometer & Froude Hofmann eddy current \\
& dynamometer \\
& Max. power:250 kW \\
& Max. torque: $1200 \mathrm{~N} \mathrm{~m}$ \\
Fuel flow meter & Max. speed: 6000 rpm \\
Air flow meter & Kobold positive displacement flow meter \\
Crank angle encoder & BOSCH air flow meter \\
Cylinder gas pressure sensor & 2614A Type \\
Combustion data acquisition & Kistler Piezoelectric Pressure Sensor 6056A \\
$\quad$ unit & Dewe-30-8-CA \\
\hline & \\
\hline
\end{tabular}

until a steady operating condition is achieved. Afterward, the fuel was changed to the biodiesel blend. To ensure the removal of residual diesel in the fuel line, the engine was run for $5 \mathrm{~min}$, and then data acquisition started. After each test, the engine was again run with diesel to drain out all the blends in the fuel line. This procedure was followed for all the blends.

In this study, the engine was operated under fully loaded conditions at different engine speeds ranging from $1000 \mathrm{rpm}$ to $4500 \mathrm{rpm}$ at an interval of $500 \mathrm{rpm}$. Initially, engine performance and emission were tested by using petroleum diesel under full load, variable speed, and non-turbocharged condition. The result was then considered as a baseline for comparison. The engine performance and emission data for petroleum diesel (OD), P20 (blend of $20 \%$ PB and $80 \%$ petroleum diesel), and PC20 were recorded under non-turbocharged and turbocharged conditions for full load and variable speed. Each test was performed thrice to avoid random errors. The REO-dCA data acquisition unit was used to collect engine performance data. The data collected under non-turbocharged conditions are represented as P20 and PC20. Conversely, P20-T and PC20-T represent data under turbocharged conditions.

\subsection{Statistical analysis}

Instrument selection, condition, calibration, environment, observation, reading, and test procedure are the sources of errors and uncertainties of an experiment. Table 6 contains the measurement range and accuracy of the instruments used in this experiment. Statistical analysis is required to prove the accuracy of the data of the experiments. Statistical analysis was carried out using Microsoft Excel 2013 by applying two-tailed Student's $t$-test to test independent variables for significant differences among sample set means. Differences between mean values at a level of $p=0.05(95 \%$ confidence level) were considered statistically significant.

\section{Results and discussions}

\subsection{Fuel properties}

From the experimental fuel properties of $C B, P B$, and $O D$ (Table 2), the densities of all biodiesels are significantly close to one another and approximately 3-3.5\% higher than the density of petroleum diesel. The kinematic viscosities of CB and PB are also very close to each other. A large variation is observed in terms of induction time. PB had an induction time close to the ASTM standard $(3 \mathrm{~h})$, whereas $C B$ had the highest induction time $(5.12 \mathrm{~h})$. The flash points of all biodiesels are satisfactorily high, except that the value for $\mathrm{CB}$ is close to the minimum ASTM limit $\left(130^{\circ} \mathrm{C}\right)$. The average calorific value (CV) of the biodiesels is $11 \%$ lower than that of OD. CB obtained the lowest CV $(36.98 \mathrm{~kJ} / \mathrm{g})$. The $\mathrm{CN}$ of the biodiesels is higher than that of OD.

The comparison of the theoretical and experimental blended fuel properties shows that the deviations of density, kinematic viscosity, and CV are lower than $2 \%$. However, the deviations occasionally exceed the $5 \%$ limit for induction time and flash point 
Table 6

List of measurement equipment and their uncertainty.

\begin{tabular}{llll}
\hline Measurement & Measurement range & Accuracy & Measurement techniques \\
\hline Load & $\pm 600 \mathrm{~N} \mathrm{~m}$ & $\pm 0.1 \mathrm{~N} \mathrm{~m}$ & Strain gauge type load cell \\
Speed & $0-10,000 \mathrm{rpm}$ & $\pm 1 \mathrm{rpm}$ & Magnetic pick up type \\
Time & - & $\pm 0.1 \mathrm{~s}$ & - \\
Fuel flow measurement & $0.5-36 \mathrm{~L} / \mathrm{h}$ & $\pm 0.04 \mathrm{~L} / \mathrm{h}$ & Positive displacement gear wheel flow meter \\
Airflow measurement & $0.25-7.83 \mathrm{~kg} / \mathrm{min}$ & $\pm 0.07 \mathrm{~kg} / \mathrm{min}$ & Hot-wire air-mass meter \\
$\mathrm{CO}$ & $0-10 \% \mathrm{by} \mathrm{vol}$. & $\pm 0.02 \%$ & Non-dispersive infrared \\
$\mathrm{CO}_{2}$ & $0-18 \% \mathrm{by} \mathrm{vol}$. & $\pm 0.03 \%$ & Non-dispersive infrared \\
$\mathrm{HC}$ & $0-9999 \mathrm{ppm}$ & $\pm 1 \mathrm{ppm}$ & Non-dispersive infrared \\
$\mathrm{NO}$ & $0-5000 \mathrm{ppm}$ & $\pm 1 \mathrm{ppm}$ & Electrochemical \\
Smoke & $0-100 \%$ & $\pm 0.1 \%$ & Photodiode detector \\
Pressure sensor & $0-25,000 \mathrm{kPa}$ & $\pm 10 \mathrm{kPa}$ & Piezoelectric crystal type \\
Crank angle encoder & $0-12,000 \mathrm{rpm}$ & $\pm 0.125^{\circ}$ & Incremental optical encoder \\
Computed & & & - \\
Brake power & - & $\pm 0.03 \mathrm{~kW}$ & - \\
BSFC & - & $\pm 0.30 \mathrm{~g} / \mathrm{kW} \mathrm{h}$ & - \\
\hline
\end{tabular}

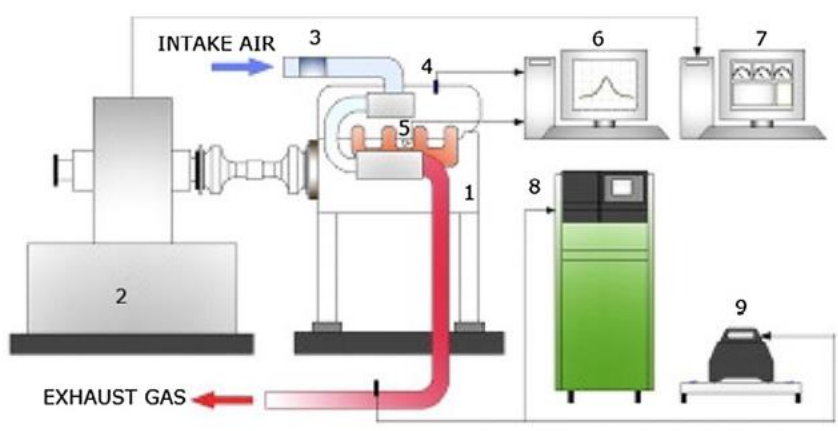

1 TEST ENGINE 2 EDDY CURRENT DYNAMOMETER 3 AIR MASS SENSOR

4 PRESSURE SENSOR 5 ACCELEROMETER 6 DATA ACQUISITION SYSTEM

7 DYNAMOMETER CONTROLLER 8 BOSCH GAS ANALYZER 9 SMOKE OPACITY METER

Fig. 1. Schematic diagram of the engine test bed.

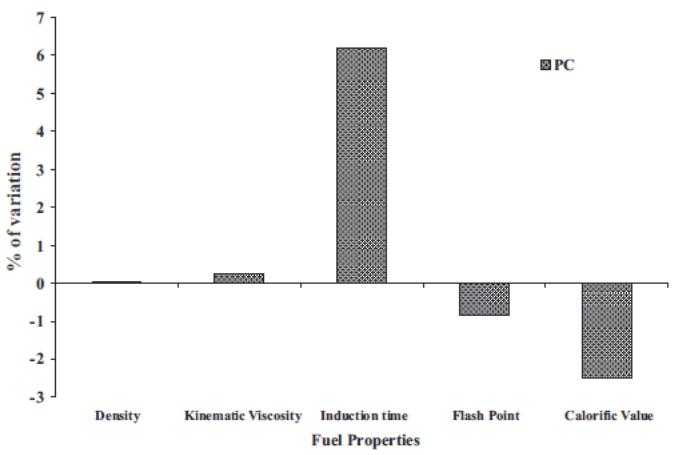

Fig. 2. Percentage (\%) of variation between theoretical and experimental blended fuel properties.

because these two properties are affected by the chemical composition and molecular structure of fuel.

Fig. 2 illustrates the variation between the theoretical (obtained using the optimum blend ratio and the linear equations used in MATLAB) and experimental (obtained from the laboratory tests) fuel properties. In reference to the induction time and the flash point, the variation is relatively high (maximum $8.5 \%$ ). For the other fuel properties, the variation is significantly low (less than $3 \%$ ), which validates the linear relationship of the fuel properties for blends.

4.2. Engine combustion and performance characteristics

The combustion pressure against crank angle diagram for biodiesel blends and baseline diesel is illustrated in Fig. 3, with focus on the "hot" part around the top dead center (TDC) at the maximum torque condition (full load, $2000 \mathrm{rpm}$ ). The pressure data of 100 cycles with a resolution of $0.1^{\circ} \mathrm{CA}$ are averaged to study the characteristics of combustion pressure. Fig. 3 shows that for the non-turbocharged condition, peak pressures occurred at almost the same crank angle for all the fuel blends. In addition, peak pressure values are also more or less similar. P20 and PC20 obtained peak pressure values of 69.5 and 70.24 bars, respectively, which are similar to diesel peak pressure value of 69.80 bars. A slightly higher peak pressure for PC20 over diesel can be attributed to coconut biodiesel that has a higher CN [35], which leads to shorter ignition delay and earlier start of combustion (SOC), as shown in Fig. 4. Under the turbocharged condition, P20 and PC20 obtained peak pressure values of 96.4 bars at $5.3^{\circ} \mathrm{CA}$ and 101.78 bars at $4.9^{\circ} \mathrm{CA}$. PC20 showed a noticeable pressure difference compared with the other biodiesel blends, and the reason is analogous to the non-turbocharged condition. 

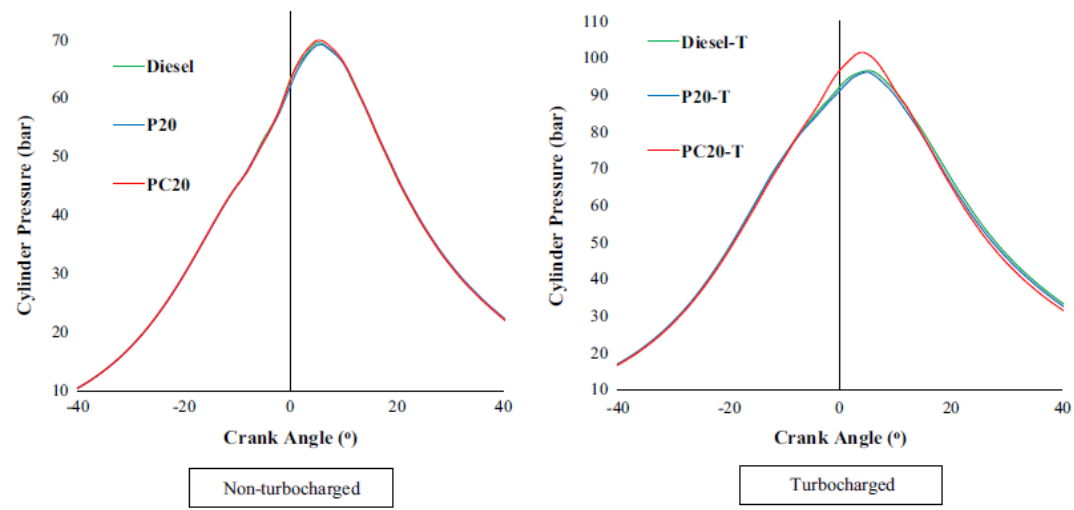

Fig. 3. Cylinder pressure at $2000 \mathrm{rpm}$.
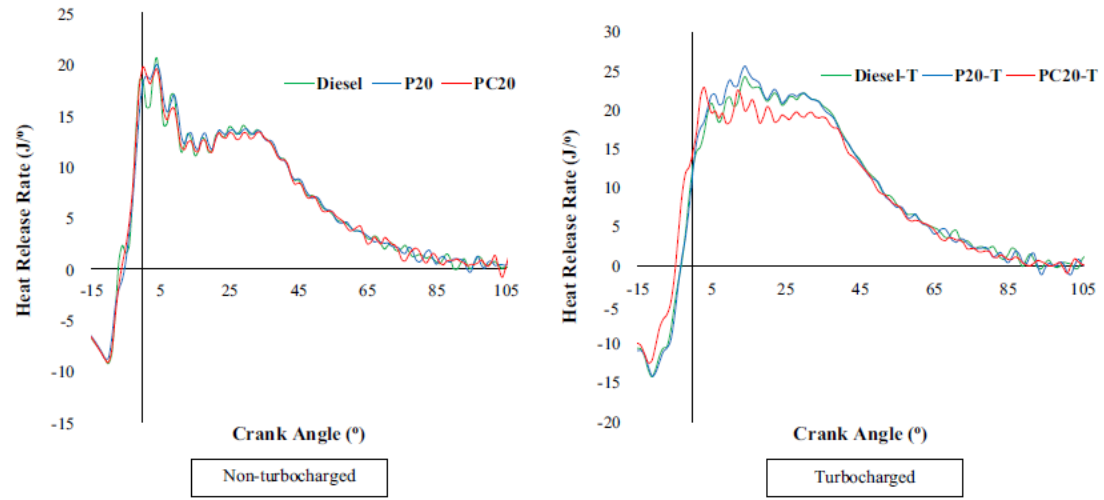

Fig. 4. Heat release rate at $2000 \mathrm{rpm}$.
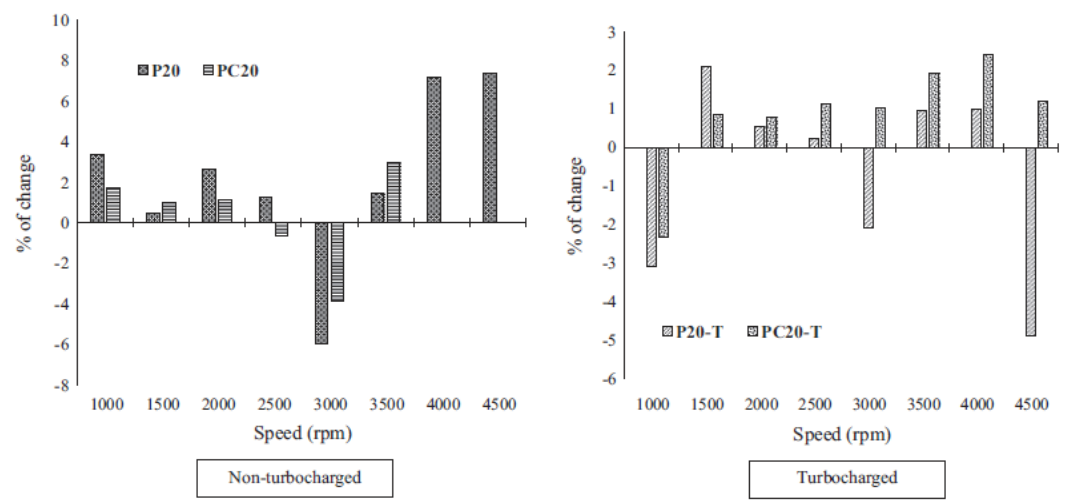

Fig. 5. Percentage (\%) change of brake power with respect to diesel at different speeds. 

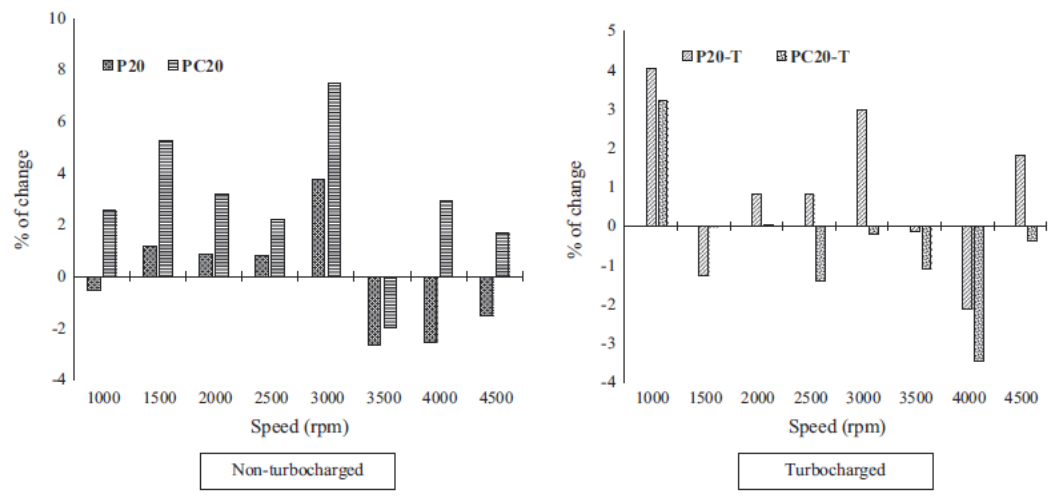

Fig. 6. Percentage (\%) change of BSFC with respect to diesel at different speeds.
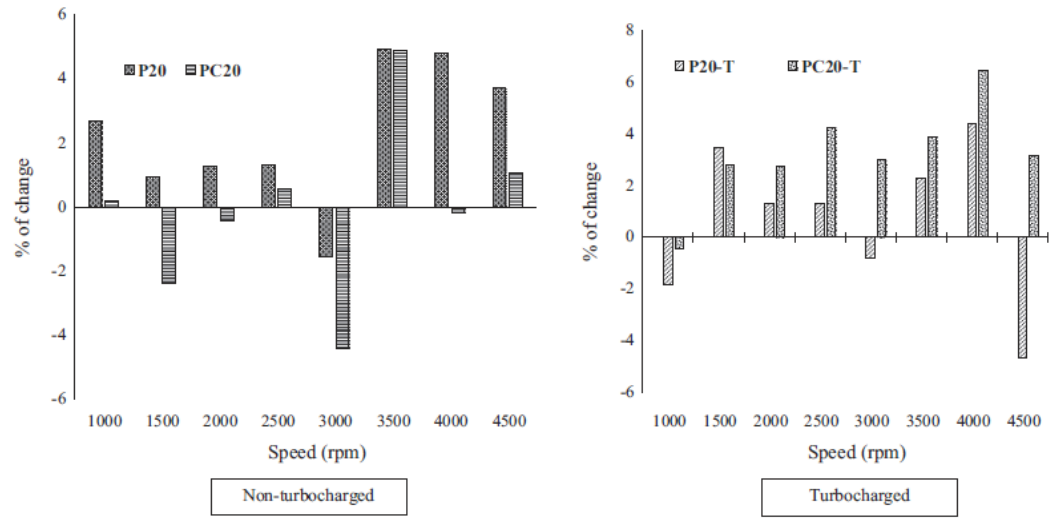

Fig. 7. Percentage (\%) change of brake thermal efficiency with respect to diesel at different speeds.
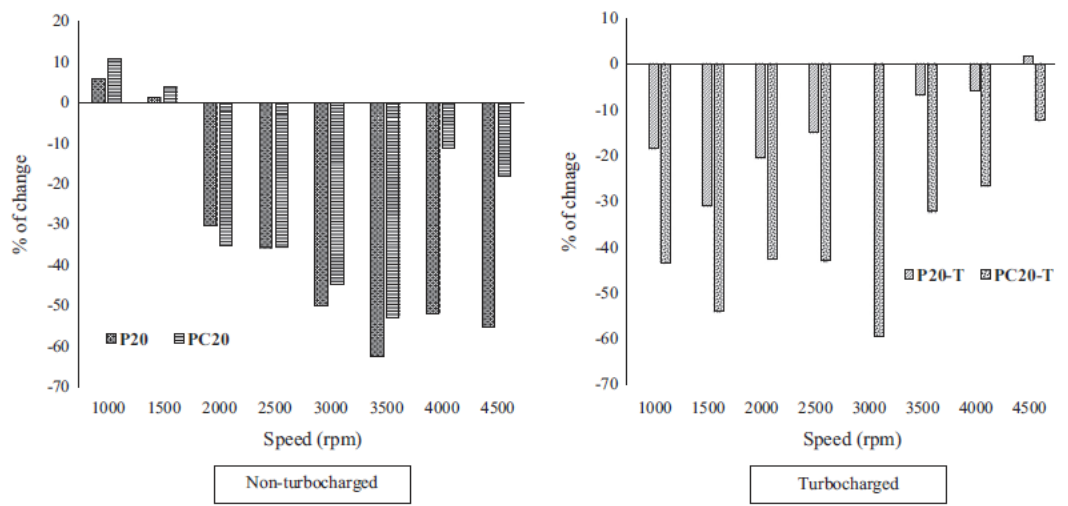

Fig. 8. Percentage (\%) change of $\mathrm{CO}$ emission with respect to diesel with engine speed variation. 

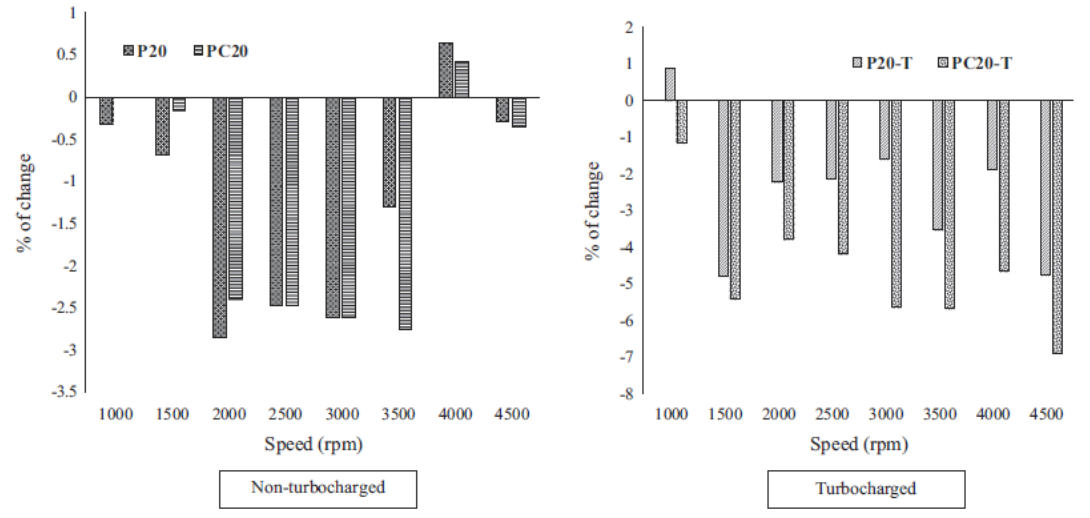

Fig. 9. Percentage (\%) change of $\mathrm{CO}_{2}$ emission with respect diesel with engine speed variation,

Heat release rate analysis is the most convenient way to learn about the combustion mechanism. This method simplifies the identification of SOC timing and differences in combustion rates. Among the approaches to compute heat release rate, the zero dimensional model was used in this study [36]. Heat release rate was calculated according to the first law of thermodynamics in this model. Cylinder volume was calculated by using cylinder geometry as a function of the CA. However, Fig. 4 shows that for all the biodiesel blends, combustion started earlier and the initial heat release rate (at pre-mixed combustion zone) is higher than diesel. This observation can be attributed to the higher $\mathrm{CN}$ of biodiesels [35]. Afterward, at the diffusion-controlled zone, the heat release rates of all the fuels are more or less similar. For turbocharged condition, SOC occurred somewhat earlier for all the fuels compared with that of the non-turbocharged condition. SOC and heat release rate were higher (except in PC20) for the biodiesel blends, which is similar to the non-turbocharged condition. The heat release rate of PC20 was significantly lower in the diffusion-controlled zone, which can be attributed to its relatively low calorific value [37]. However, the initial heat release rate of PC20 was the highest because of its high $\mathrm{CN}$ (due to the higher $\mathrm{CN}$ of coconut biodiesel), which is analogous to the non-turbocharged condition.

Fig. 5 illustrates the engine brake power at full load operating condition. On average, P20 and PC20 show $2 \%$ and $0.3 \%$ higher brake power, respectively, than OD under the non-turbocharged condition. Conversely, under the turbocharged condition, only PC20 shows an average of $1 \%$ higher brake power, whereas P20 shows about $0.6 \%$ reduction. Unlike the values in OD, these changes were significant at $0.01<p<0.03$. The earlier SOC and the higher heat release caused higher average cylinder pressure for biodiesel blends and resulted in higher power. The presence of additional oxygen in biodiesel provides better combustion and higher heat release. Although PC20 showed the maximum peak pressure, a lower heat release rate in the diffusion-controlled zone caused a pressure drop and lower brake power than other biodiesel blends under the non-turbocharged condition. However, under the turbocharged condition, the higher peak pressure and the higher initial heat release rate of PC20 compared with other biodiesels compensate for the effect of lower heat release rate in the diffusion-controlled zone, and it showed the maximum increment of power throughout the test.

Fig. 6 shows the percentage change in brake-specific fuel consumption (BSFC) of the engine for all blends with respect to pure OD at different engine speeds. P20 shows slightly lower BSFC, whereas PC20 shows higher BSFC than that of OD in the non-turbocharged condition. In the turbocharged condition, the opposite trend was observed. PC20 showed a $2.0 \%$ increase, and P20 showed a $1.8 \%$ increase in mean BSFC compared with OD in the non-turbocharged and turbocharged conditions, respectively. Compared with $\mathrm{OD}$, these changes were significant at $0.01<p<0.02$. The higher BSFC can be attributed to the higher densities and viscosities of the blends together with their lower energy densities compared with OD [38]. At higher speeds, lower BSFC was observed because of better combustion despite the short combustion period and the increased fuel amount [39]. The oxygen content of biodiesel might be used during combustion in the fuel-rich zone, which increases combustion chamber temperatures and helps in fast burning of blend molecules. The lower calorific value of $C B$ also causes the higher BSFC of PC20. In the turbocharged condition, PC20 shows the maximum reduction in fuel consumption compared with other fuels, which is even lower than that of OD in the turbocharged condition.

The brake thermal efficiency (BTE) characteristics at different speeds are presented in Fig. 7. All biodiesel blends show $0.5-6 \%$ higher BTE than that of OD throughout the test depending on speed. This observation is probably due to the fact that the oxygen-rich blends experience more complete combustion in the fuel-rich regions [40]. Under non-turbocharged conditions, irregularity is observed as the engine is designed to operate with a turbocharger. However, PC20 showed the maximum thermal efficiency under turbocharged conditions with an average of $3 \%$ increase than that of OD. Conversely, P20 shows the maximum efficiency under non-turbocharged conditions.

\subsection{Engine emission}

The $\mathrm{CO}$ emissions for different speeds at full load are shown in Fig. 8. Biodiesel blends showed $10-60 \%$ CO reduction because of fuel-borne oxygen, lower carbon content, and higher CN [29,41]. Higher $\mathrm{CN}$ exhibits shorter ignition delay and allows better combustion. Afterward, the oxygen content of biodiesel comes into play, which enhances the combustion process. High oxygen content ensures higher in-cylinder combustion temperature, which promotes more complete combustion and therefore greater conversion of $\mathrm{CO}-\mathrm{CO}_{2}$ than for diesel fuel [42]. Under turbocharged and non-turbocharged conditions, P20 shows higher $\mathrm{CO}$ reduction than other tested fuels. Kinoshita et al. [29] and Ono et al. [27] conducted their experiments with $\mathrm{CB}$ and found that approximately 

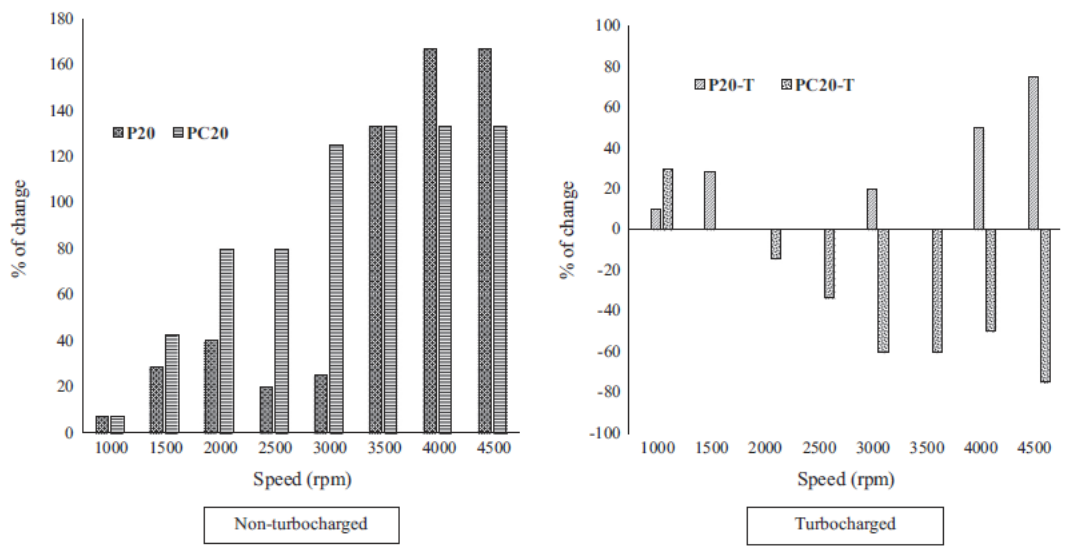

Fig. 10. Percentage (\%) change of HC emission with respect to diesel with engine speed variation.
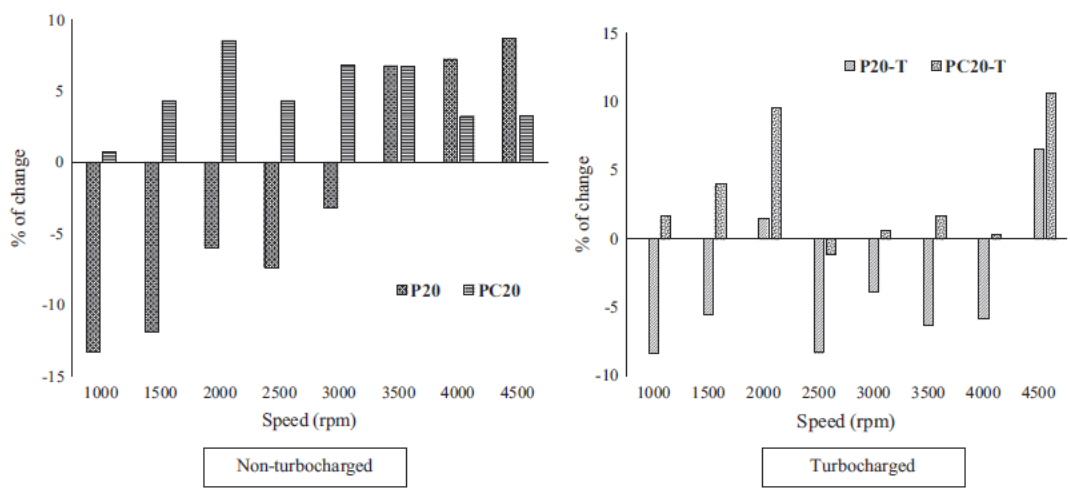

Fig. 11. Percentage (\%) change of NO emission with respect to diesel with engine speed variation.

$3 \%$ higher oxygen than other biodiesels and the presence of $\mathrm{CB}$ in the blend reduces CO emission by $30-40 \%$ and $45-60 \%$ respectively. Sanjid et al. [26] also reported $10-12 \%$ reduction of $\mathrm{CO}$ emission compared to baseline diesel. Higher oxygen content of $\mathrm{CB}$ was reported to be the cause of emission reduction.

The results for $\mathrm{CO}_{2}$ emission are shown in Fig. 9. For all biodiesel blends, $\mathrm{CO}_{2}$ emission is lower than that of $\mathrm{OD}$ in most cases because of the low carbon content of biodiesel [29,41]. Under turbocharged conditions, a large reduction in $\mathrm{CO}_{2}$ is observed, and PC20 shows the on average $4-7.5 \%$ reduction. Ono et al. [27] also found $7-10 \%$ lower $\mathrm{CO}_{2}$ emission, on average, using blends of binary biodiesel.

The results for HC emission are shown in Fig. 10. Under non-turbocharged conditions, all the biodiesel blends provide significantly higher HC than OD. Under turbocharged conditions, all biodiesel blends reduced HC emission except for P20. The high HC emission in biodiesel blends is driven by different factors, such as ignition delay, fuel mixing, spray pattern, and response of measuring equipment, and its theoretical study is still in its infancy [43]. However, under turbocharged conditions, PC20 shows a higher reduction (20-80\%) in HC emission than others. The presence of CB in PC20 reduces the $\mathrm{HC}$ emission because of the relatively higher (approximately $3 \%$ ) oxygen content of $\mathrm{CB}$, which results in better oxidation
$[27,29]$. Both of these works by Kinoshita et al. [29] and Ono et al. [27] reported $40-50 \%$ and $30-50 \%$ reduction of $\mathrm{HC}$ emission compared to baseline diesel.

The NO emission characteristics are shown in Fig. 11. With increasing engine speed, NO emission increases because of high combustion temperature. At the maximum speed (4500 rpm), NO emission is reduced because of a short combustion time. The lowe calorific value of biodiesel results in a lower combustion temperature and a decreased NO emission [44]. P20 shows the lowest NO emission, whereas PC20 shows the highest. P20 showed $2.4 \%$ and $3.8 \%$ decrease in the average of $\mathrm{NO}$ emission compared with that of OD in non-turbocharged and turbocharged conditions, respectively. Conversely, PC20 showed $4.8 \%$ and $3.4 \%$ increase in the average NO emission compared with that of OD in non-turbocharged and turbocharged conditions, respectively. Compared with $\mathrm{OD}$, these changes were significant at $0.01<p<0.02$. The high oxygen concentration of $\mathrm{CB}$ influences $\mathrm{NO}$ emission. Moreover, the early SOC and the high initial heat release rate (Fig. 4) indicate higher pre-mixed combustion, which contributes to the higher NO emission of PC20 [45]. Average $10 \%$ and $8 \%$ higher nitrogen oxides emission using binary biodiesel blends compared to baseline diesel were also reported by Sanjid et al. [26] and Kinoshita et al. [29] respectively.

\section{Link to Full-Text Articles :}

